\title{
NECTIN4 promotes papillary thyroid cancer cell proliferation, migration, and invasion and triggers EMT by activating AKT
}

This article was published in the following Dove Press journal: Cancer Management and Research

\section{Ru-Tian Hao* \\ Chen Zheng* \\ Chen-Yong Wu \\ Er-Jie Xia \\ Xiao-Fen Zhou \\ Rui-Da Quan \\ Xiao-Hua Zhang}

Department of Thyroid and Breast Surgery, The First Affiliated Hospital of Wenzhou, Medical University, Wenzhou, Zhejiang, People's Republic of China

*These authors contributed equally to this work.
Correspondence: Xiao-Hua Zhang Department of Thyroid and Breast Surgery, The First Affiliated Hospital of Wenzhou, Medical University, Nanbai Xiang, 325000, Wenzhou, Zhejiang, People's Republic of China Email oncology_zhang@outlook.com

\begin{abstract}
Papillary thyroid cancer (PTC) is the most frequent type of malignant thyroid cancer, but its molecular mechanisms remain unknown. To better understand the tumorigenesis and progression of PTC, we conducted a comprehensive analysis of the wholetranscriptome resequencing of paired PTC and normal thyroid tissues. Nectin cell adhesion molecule 4 (NECTIN4) was significantly overexpressed in thyroid carcinoma compared with that in matched normal tissue. We also assessed the relation between the expression level of NECTIN4 and the clinicopathological features of PTC in The Cancer Genome Atlas database, and results showed that upregulated NECTIN4 is associated with lymph node metastasis $(P<0.001)$ and tumor size $(P=0.017)$. The biological function of NECTIN4 was also investigated by using the PTC cell lines TPC-1 and KTC-1. In vitro experiments demonstrated that NECTIN4 downregulation significantly inhibits the colony formation, proliferation, migration, and invasion of PTC cell lines. NECTIN4 could modulate the expression of epithelial-mesenchymal transition-related proteins via the PI3K/AKT pathway, and SC79, an AKT phosphorylation activator, could reverse the si-RNA knockdown effect. In addition, after the use of AKT inhibitors (LY 294,002), we found that SiRNA have similar effect with AKT inhibitors. Taking the results together, the current study shows that NECTIN4 has important biological implications in the tumorigenesis and metastasis of PTC and may be a potential therapeutic target for the disease.
\end{abstract}

Keywords: NECTIN4, PTC, AKT

\section{Introduction}

In recent decades, thyroid cancer has become a common endocrine malignancy with a rapidly increasing global incidence. The US National Cancer Institute estimated 56,870 new cases and 2,010 deaths due to thyroid cancer in the USA in 2017. ${ }^{1,2}$ By comparison, the National Office for Cancer Prevention and Control estimated 90,000 new cases and 6,800 deaths due to the disease in China. ${ }^{3}$ The major types of thyroid cancer include papillary thyroid carcinoma (PTC) and follicular thyroid carcinoma (FTC); of these, PTC accounts for $75 \%-80 \%$ of all thyroid cancer cases. $^{4}$ While the morbidity of PTC has rapidly increased, the disease is generally considered relatively curable. ${ }^{5}$ After total thyroidectomy and radio-iodinated therapy, patients with PTC show satisfactory prognosis and an overall 10-year survival rate of $90 \%{ }^{6}$ However, although PTC generally follows an indolent clinical course and carries excellent prognosis, it is still highly metastatic and recurrent after routine treatment. Lymph node metastasis has been shown to occur in $20 \%$ of all 
PTC patients, and regional recurrence has been reported to occur in $10 \%$ of those patients who underwent total thyroidectomy. $^{7}$ Therefore, early and accurate diagnosis is vital for physicians to provide an appropriate treatment approach and improve a patient's quality of life.

Developments in next-generation sequencing (NGS) have enabled numerous researchers to examine the mechanism of thyroid cancer and make a remarkable progress in the field. For instance, B-type Raf kinase V600E mutations have been proven to promote PTC tumorigenesis and progression by aberrantly activating the mitogenactivated pathway kinase pathway. ${ }^{8} T E R T$, RAS, and PI3K gene mutations also demonstrate promising prognostic value in PTC patients. $^{9-11}$ However, although relevant research has been performed, several PTC characteristics remain incompletely understood. To describe the progression of PTC, we performed a comprehensive analysis of the whole-transcriptome resequencing of 19 pairs of primary thyroid cancer samples with matched adjacent normal thyroid tissues. Through bioinformatics, we show that NECTIN4 may be a potential oncogenic gene associated with PTC. ${ }^{12}$

The nectin cell adhesion molecule (NECTIN) family, a group of $\mathrm{Ca}^{2+}$-independent immunoglobulin-like molecules, consists of four members (NECTIN1 to NECTIN4). NECTIN1 to NECTIN3 are widely expressed in normal adult tissue, whereas NECTIN4 expression is overexpressed in cancer tissues. ${ }^{13}$ Interestingly, the main function of NECTIN4 is to mediate cell-cell adhesion via the organization of epithelial and endothelial junctions. NECTIN4 is the epithelial cell receptor for canine distemper virus and has been involved in neurovirulence. ${ }^{14}$ Overexpression of the molecule is associated with poor outcomes in lung, breast, and ovarian cancers. ${ }^{15-17}$ Interactions in the NECTIN-AFADIN (encoded by Mllt4) complex have been shown to ultimately enhance cell survival and prevent apoptosis by activating the phosphoinositide 3-kinase (PI3K)-AKT signaling pathway. ${ }^{18}$

To better understand the mechanism of PTC occurrence and progression, we collected 44 paired PTC tissue samples as a validated cohort and performed a comprehensive analysis of their whole-transcriptome resequencing; bioinformatics analysis was also performed to investigate their mRNA expression. We then evaluated the relationship between NECTIN4 expression and the clinical and molecular features of PTC both in The Cancer Genome Atlas (TCGA) cohort and our validated cohort. Next, using cell culture experiments and western blotting, we established that NECTIN4 depletion effectively inhibits the proliferation and invasion of two PTC cell lines (ie, TPC1 KTC-1) in vitro and induces cell apoptosis. Knockdown of NECTIN4 by small interfering RNA (siRNA) in those cell lines decreased the EMT related protein expression of $\mathrm{N}$-cadherin, E-cadherin, Enhancer of zeste homolog 2 (EZH2). In addition, we determined that AKT is involved in the oncogenic function of NECTIN4-mediated cell proliferation and migration.

SC79 is a specific AKT-binding substance that can directly bind to AKT and convert AKT from an inactive conformation to an active one, leading to AKT hyperactivation. ${ }^{19}$ In this work, we determined that activated AKT can enhance thyroid cancer (TPC-1, KTC-1) cell migration and proliferation and partially reverse the siRNA knockdown effect. At same time, we found that siRNA have generally consistent inhibition effect with a strong AKT inhibitor (LY 294,002).

Our study aims to (a) analyze the relationship between NECTIN4 expression and the clinical and molecular features of PTC and (b) determine the role of NECTIN4 in the proliferation and metastasis of thyroid carcinoma.

\section{Materials and methods}

\section{Patients and samples}

We did RNA sequencing of 19 pairs of thyroid cancer and adjacent non-cancerous tissues in our previous study. The samples were taken from patients who underwent surgery at the First Affiliated Hospital of Wenzhou Medical University from September 2014 to March 2015. None of the those samples underwent preoperative treatments, such as chemotherapy or radiotherapy. We also collected 44 fresh PTC tissue samples and matched these with adjacent normal thyroid tissue samples as a validated cohort. The samples were obtained from patients who had undergone surgical treatment without underwent preoperative treatments, such as chemotherapy or radiotherapy. The samples were frozen in liquid nitrogen immediately after lesion resection and then stored at $80{ }^{\circ} \mathrm{C}$ before RNA extraction. All tumor tissues were histologically reviewed by two pathologists, and the cases were retrospectively reviewed by two senior pathologists to confirm the histological diagnosis. Patients provided signed informed consent, and study protocols for the use of human tissues were approved by and performed in accordance with the ethical standards of the Ethics Committee of the said hospital and the Declaration of Helsinki. 
Thyroid cancer RNA-seq data and corresponding clinical information were downloaded from the TCGA database. (https://tcgadata.nci.nih.gov/tcga/). In total, 502 PTC sequence data with complete clinical features and 58 pairs of thyroid cancer with matched normal tissues were selected.

RNA isolation and reverse transcription-quantitative PCR (RT-qPCR) analysis

Total RNA was isolated from the tissue specimens or cell lines using TRIzol ${ }^{\circledR}$ reagent (Invitrogen; Thermo Fisher Scientific, Waltham, MA, USA) according to the manufacturer's standard protocol. To assess RNA quality and quantity, A260/A280 ratios and spectrophotometry were respectively applied. Real-time PCR analysis was performed in triplicate on an ABI Prism 7,500 sequence detection system (Thermo Fisher Scientific) using the THUNDERBIRD SYBR qPCR Mix (TOYOBO) following the user's guide. The primer sequences for PCR were as follows: NECTIN4, forward 5'GCAGTGATTATAGACCGAGAG-3' and reverse 5'-AC ATCCAGAAGAGCCTTGA-3'; GAPDH, forward 5'-GGT CGG AGT CAA CGG ATT TG-3' and reverse 5'-ATG AGC CCC AGC CTT CTC CAT-3'.

PCR was performed in $20 \mu \mathrm{l}$ reaction systems containing $1 \mu \mathrm{l}$ of cDNA $+7 \mu \mathrm{l}$ of RNA-free water $+0.8 \mu \mathrm{l}$ of the forward primer $+0.8 \mu \mathrm{l}$ of the reverse primer $+0.4 \mu \mathrm{l}$ of $\mathrm{ROX}+10 \mu \mathrm{l}$ of Thunderbird SYBR qPCR Mix; the concentration of the primers was $0.2 \mu \mathrm{M}$. The PCR program comprised several steps: step 1: $95^{\circ} \mathrm{C}$ for $2 \mathrm{~min}$, step $2: 95^{\circ} \mathrm{C}$ for $15 \mathrm{~s}$, and step 3: $60^{\circ} \mathrm{C}$ for $60 \mathrm{~s}$. Steps 2 and 3 were repeated for 40 cycles, and a final step of $72{ }^{\circ} \mathrm{C}$ for $5 \mathrm{~min}$ was performed. GAPDH was used as the internal control, and relative expression levels were calculated using the $2^{-\Delta \Delta C q}$ method.

\section{Materials}

All chemicals were acquired commercially. Roswell Park Memorial Institute 1640 (RPMI 1640) medium was purchased from Gibco-BRL (NY, USA). Antibodies against $\mathrm{AKT}, p$-AKT, and $\beta$-actin were purchased from Abcam (Shanghai, China) and freshly prepared. SC79 was purchased from MedChem Express (MCE, Monmouth Junction, USA). The concentration of SC79 was $10 \mathrm{mM}$; LY294002 was purchased from MedChem Express (MCE, USA). The concentration of LY294002 was $25 \mathrm{mM}$, and all reagents were dissolved in DMSO.

\section{Cell lines and cell culture}

The human thyroid cancer cell lines TPC1 and BCPAP were provided by Professor Mingzhao Xing of Johns
Hopkins University School of Medicine (Baltimore, MA, USA). KTC-1 and HTORI3 cell lines were purchased from Stem Cell Bank, Chinese Academy of Sciences. Using above cell lines were approved by the Ethics Committee of the First Affiliated Hospital of Wenzhou Medical University. These cell lines were cultured in RPMI 1640 (Invitrogen; Thermo Fisher Scientific) supplemented with $10 \%$ fetal bovine serum (FBS; Invitrogen; Thermo Fisher Scientific), $1 \times$ MEM nonessential amino acids, and $1 \times$ sodium pyruvate. All cells were maintained in a humidified incubator at $37{ }^{\circ} \mathrm{C}$ with $5 \% \mathrm{CO}_{2}$. TPC1 and KTC-1 cells were plated onto six-well plates at concentrations of $4 \times 10^{5}$ and $8 \times 10^{5}$ cells/well, respectively, and incubated for $24 \mathrm{~h}$ in growth medium.

\section{Cell transfection}

For cell interference, NECTIN4 siRNA was synthesized at Shanghai GenePharma Co., Ltd. The sequences of the NECTIN4 are as follows: NECTIN4 (Sense-1: GCAUCUACGUCUGCCAUGUTT; Antisense-1: ACA UGGCAGACGUAGAUGCTT; Sense-2: GGAGGAAGA UCAGGAUGAATT; Antisense-2: UUCAUCCUGAUCU UCCUCCTT); scramble sequences as negative controls (si-NC)in our experiments. The scramble sequences are randomly added with no any target sequence tracks. Briefly, cells were seeded into six-well plates. After $24 \mathrm{~h}$, siRNA was transfected into cells using Lipo iMAX (Invitrogen, Grand Island, NY, USA) according to the user guide. Final siRNA concentrations of $100 \mathrm{nM}$ for TPC-1 and $75 \mathrm{nM}$ for KTC-1 were produced. Cells were harvested $48 \mathrm{~h}$ after transfection for subsequent RNA expression analysis. All knockdown experiments were performed in triplicate.

\section{CCK-8 proliferation assay}

For the proliferation assay, TPC 1 and KTC- 1 cells $\left(2 \times 10^{3}\right.$ cells) were seeded into 96-well plates and then transfected with siRNA. After cell adherence, $10 \mathrm{~mL}$ of CCK-8 solution was added to each well, and the cells were incubated at $37{ }^{\circ} \mathrm{C}$ for $2-4 \mathrm{~h}$. All cell plates were continuously incubated at $37^{\circ} \mathrm{C}$ for 5 consecutive days. Cell proliferation curves were drawn by measuring the absorbance of the wells at $450 \mathrm{~nm}$.

\section{Colony formation assay}

For the colony formation assay, transfectant cells or control cells $\left(2 \times 10^{3}\right.$ cells for TPC1 and KTC- 1$)$ were seeded into 
six-well plates, incubated for 8-14 days, fixed with $4 \%$ paraformaldehyde (PFA; Sigma-Aldrich Co., St. Louis, MO USA) for $30 \mathrm{~min}$, and then stained with $0.01 \%$ crystal violet for $30 \mathrm{~min}$. All assays were performed in triplicate.

\section{Migration and invasion assay}

To detect cell migration, we used cell culture chambers according to the manufacturer's instructions (Corning Costar Corp., Cambridge, MA, USA), we first used trypsin digested cells and then collected cells with medium containing $10 \%$ FBS. Transfectant cells or control cells $\left(5 \times 10^{4}\right.$ cells) (approx. $250 \mathrm{~mL}$ ) were transferred into the upper chamber, and the lower chamber was filled with $600 \mathrm{~mL}$ of medium containing $10 \%$ FBS. Then, the plate was placed in the incubator for $24 \mathrm{~h}$. The membrane was fixed with $4 \%$ PFA and stained with $0.4 \%$ crystal violet solution for $20 \mathrm{~min}$. Matrigel invasion performed using a procedure similar to that used for the migration assay. Cell migration and invasion ability were assessed by counting the cells that had migrated through the membrane. A total of five random fields of view were selected, and images were captured by a microscope at $20 \times$ magnification.

\section{Determination of the effect of various concentrations of NECTIN4 at on the apoptotic rates of thyroid cancer cells}

Two thyroid cancer cell types (TPC1, KTC-1) in the exponential growth phase were seeded into six-well plates $\left(2 \times 10^{3}\right.$ cells for TPC1 and KTC-1) and incubated for $24 \mathrm{~h}$. The supernatant was discarded, siRNA was transfected into the cells using Lipo iMAX (Invitrogen), and final siRNA concentrations of $100 \mathrm{nM}$ for TPC-1, $50 \mathrm{nM}$ for BCPAP, and $75 \mathrm{nM}$ for KTC-1 were acquired. The cells were incubated for 48 h. EDTA-free trypsin (0.25\%) was used to detach cells, which were then divided into groups. The detached cells were washed twice and then centrifuged at 1,000 rpm for $5 \mathrm{~min}$ at $37^{\circ} \mathrm{C}$. An Annexin V/propidium iodide (PI) apoptosis detection kit and a cell proliferation and cytotoxicity assay kit (Nanjing KeyGen Biotech. Co., Ltd., Nanjing, China) were used to determine the apoptosis rates of TPC1, KTC-1, and BCPAP cells according to the manufacturer's protocol. The cells were harvested, washed twice, and resuspended in $1 \times$ binding buffer (Beyotime Institute of Biotechnology, Haimen, China) at a concentration of $1 \times 10^{6}$ cells $/ \mathrm{mL}$. Cell suspensions of $100 \mu \mathrm{l}$ were stained with $5 \mu \mathrm{l}$ of Annexin V-fluorescein isothiocyanate and $5 \mu 1$ of PI at room temperature for $15 \mathrm{~min}$ in the dark prior to analysis by flow cytometry.

\section{Protein extraction and western blot analysis}

The collected cells were lysed in cell lysis buffer (Beyotime) to obtain whole-cell lysates. since cadherins are present in membrane, we used membrane protein extraction kit (Bestbio) to obtain membrane protein from the cell lysate according to the manufacturer's standard protocol. Protein concentrations were measured using bicinchoninic acid assay (BCA). Then, total proteins in the lysate were separated by SDS-PAGE on $10 \%$ gel and electro-transferred to PVDF membranes. Next, the membranes were blocked with $5 \%$ skim milk (BD, Difco ${ }^{\text {TM }}$ Skim Milk, 232,100) for $2 \mathrm{~h}$ at room temperature. The membranes were probed with polyclonal antibody overnight at $4{ }^{\circ} \mathrm{C}$, washed thrice with TBST for $10 \mathrm{~min}$ each time, incubated with secondary antibodies (goat anti-rabbit IgG conjugated with HRP, Abcam) at room temperature for $1 \mathrm{~h}$, and then washed once more with TBST thrice for 10 min each. Finally, an ECL chromogenic substrate with HRP was used to visualize the protein bands. The band intensity was quantified using Image Lab software, and the primary antibodies used included Vimentin (Abcam, ab92547), EZH2 (Abcam, ab203254), Anti-Sodium Potassium ATPase (ab58475) and $\beta$-actin (Sigma-Aldrich Co.)

\section{Immunocytochemistry staining}

Two thyroid cancer cell types (TPC1, KTC-1) in the exponential growth phase were seeded into six-well plates and siRNA was transfected into the cells as described above. Then, the plate was placed in the incubator for $24 \mathrm{~h}$. Briefly, after treatment, the cells were washed with ice-cold PBS. Next, they were fixed for $15 \mathrm{~min}$ in cold acetone and washed using icecold PBS. After blocking in $10 \%$ normal goat serum at $37^{\circ} \mathrm{C}$ for $1 \mathrm{~h}$, the cells were washed and incubated at $37^{\circ} \mathrm{C}$ with a rabbit Vimentin, N-cadherin and E-cadherin antibody for another $1 \mathrm{~h}$. After three PBS washes of $10 \mathrm{~min}$ each, the FITCconjugated goat anti-rabbit secondary antibody was applied to the samples at $37^{\circ} \mathrm{C}$ for $1 \mathrm{~h}$. After washing thoroughly with PBS, the cells were fixed and visualized using an Olympus confocal microscope.

\section{Statistical analysis}

Data with a normal distribution are expressed as mean \pm SD and compared by Student's $t$-test. Categorical variables are expressed as percentages and compared by the $\chi^{2}$ test or Fisher's exact test, as appropriate. A $P$-value of $<0.05$ was considered to indicate a statistically significant difference. Statistical analysis was performed using SPSS software version 22.0 (IBM SPSS, Armonk, NY, USA), and GraphPad 
Prism 5 (GraphPad Software, Inc., La Jolla, CA, USA) was used to create graphs.

\section{Results}

NECTIN4 is upregulated in PTC

After whole-transcriptome resequencing of 19 pairs of tumors and adjacent normal tissues, we noted that the expression of NECTIN4 was clearly higher in tumor tissues than in adjacent normal tissues (Figure 1). To validate the data obtained through whole-transcriptome resequencing, we detected the mRNA expression of NECTIN4 in 44 pairs of PTC tumor samples and matched adjacent noncancerous tissues by qRT-PCR. The expression of NECTIN4 was significantly upregulated in the PTC samples compared with that in the matched adjacent normal tissues (Figure 2A, $P<0.0001)$. The same trend was also found in the TCGA cohort (Figure 2B, $P<0.001$ ). To investigate further, we

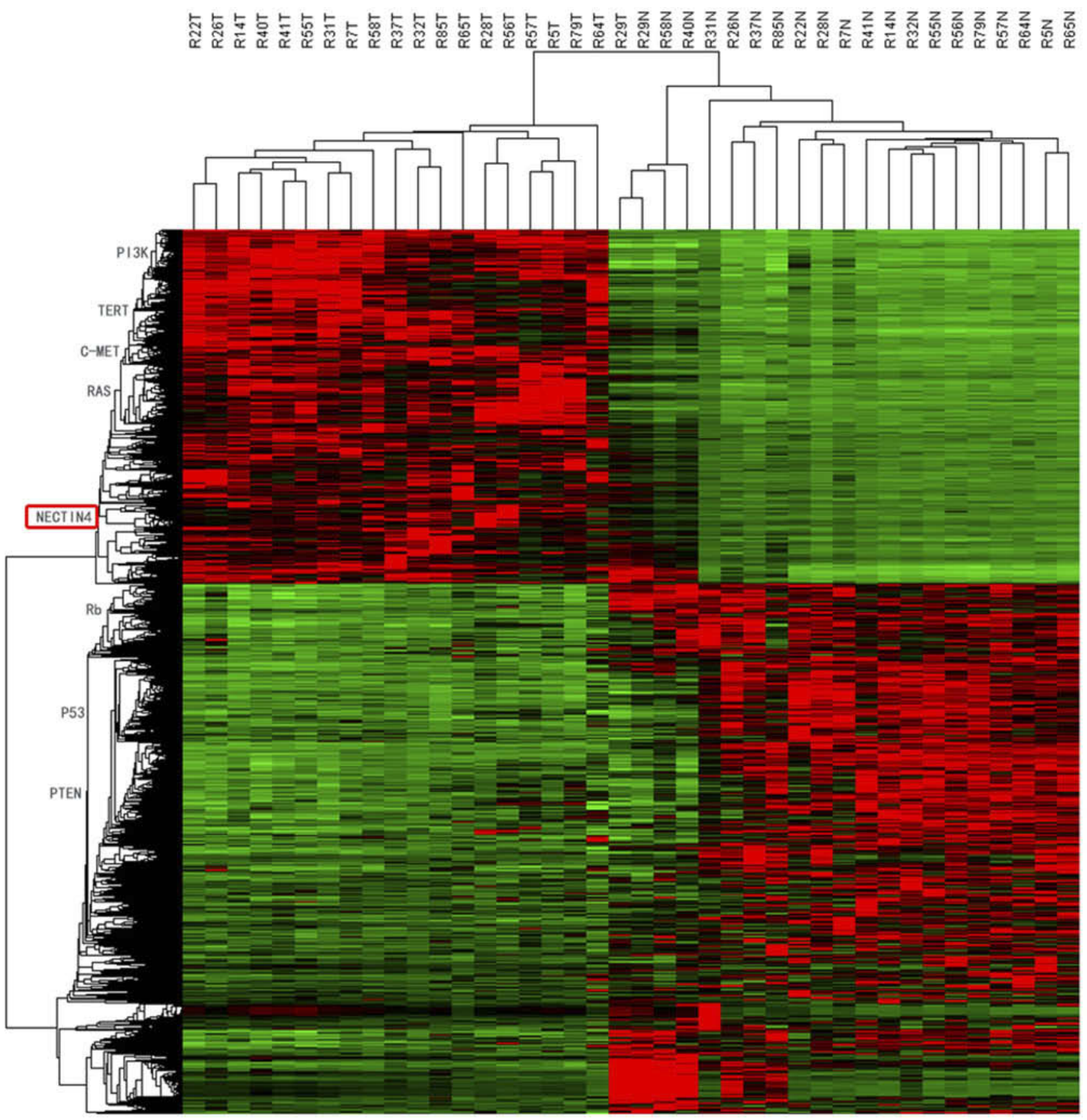

Figure I HeatMap of whole-transcriptome resequencing of 19 pairs of tumors and adjacent normal tissues. 

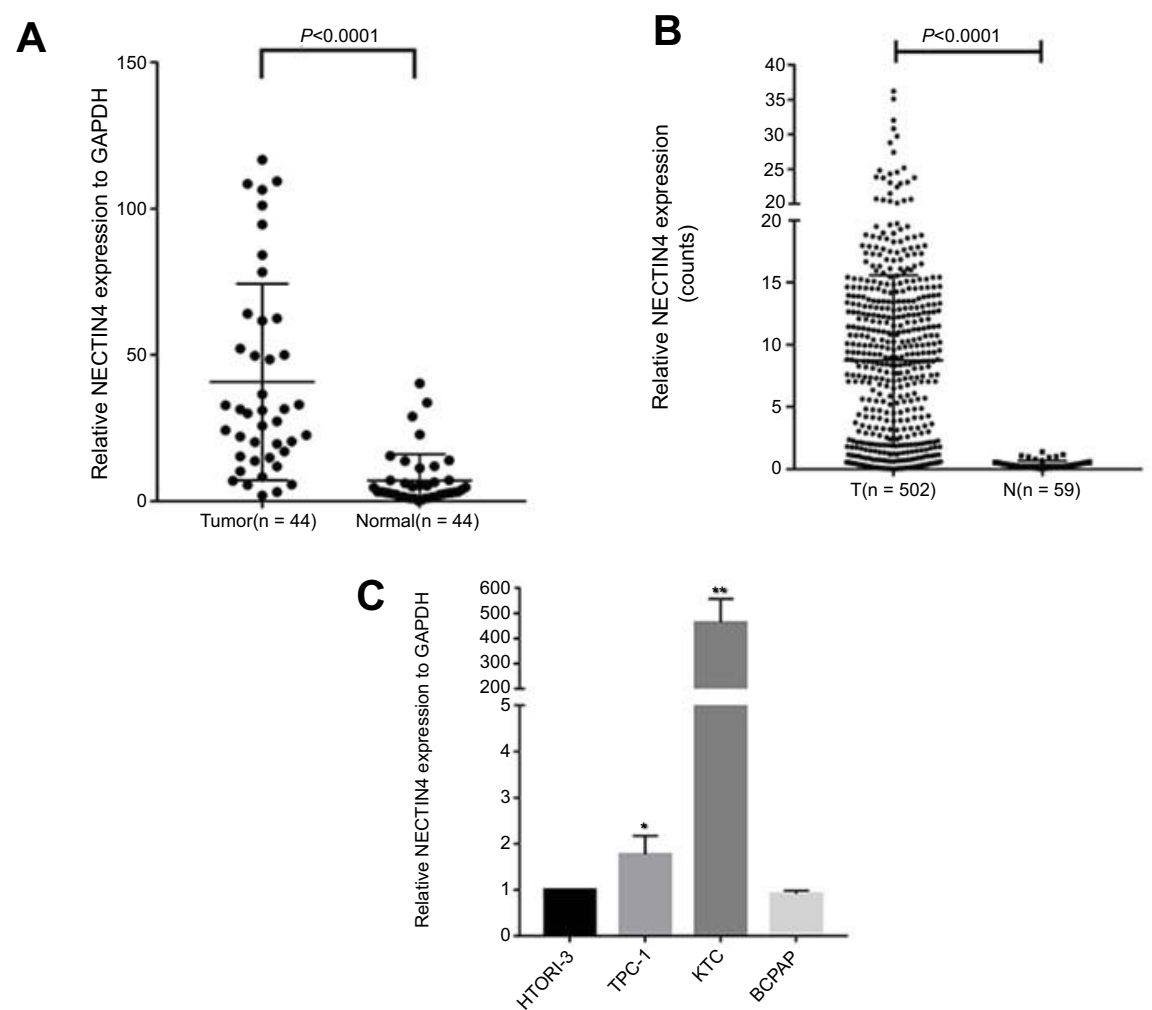

Figure 2 NECTIN4 is upregulated in PTC.

Notes: (A) The expression of NECTIN4 was significantly upregulated in the PTC samples in the our cohort (Figure IB, P<0.000I). (B) The expression of NECTIN4 was significantly upregulated in the PTC samples in the TCGA cohort. (Figure IC, $P<0.001$ ). (C) The relative expression of NECTIN4 (compared with the GAPDH gene) was examined via RT-qPCR. Compared to normal thyroid cell lines,TPC-I and KTC cell lines have higher NECTIN4 expression while BCPAP has lower expression. *P<0.05, $* * * P<0.001$ in comparison with $\mathrm{Si}-\mathrm{NC}$ or GAPDH using student's $t$-test.

Abbreviations: PCT, papillary thyroid cancer; RT-qPCR, reverse transcription-quantitative PCR; TCGA, The Cancer Genome Atlas.

examined the expression of NECTIN4 in PTC cell lines and discovered that the NECTIN4 gene is expressed at higher levels in TPC-1 and KTC than in the normal thyroid cell line HTORI3 but in BCPAP have lower level expression (Figure 2C).

\section{NECTIN4 expression is associated with the clinicopathological features of PTC}

To investigate the role of NECTIN4 in the tumorigenesis and progression of PTC, we analyzed the association NECTIN4 expression and its clinicopathological features. The patient group was divided into two groups, namely, low expression and high expression groups, according to their NECTIN4 expression based on the median value. The clinical features of the TCGA cohort are summarized in Table 1. High NECTIN4 expression was associated with lymph node metastasis $(P<0.001)$, tumor size $(P=0.017)$, histological type $(P<0.0001)$, and disease stage $(P<0.001)$ (Table 1$)$. No statistically significant associations were found between NECTIN4 expression and gender, multi-nodularity, or age in both cohorts
$(P>0.05)$. These results indicated that high NECTIN4 expression was associated with abnormal cell proliferation and influence the ability of migration of thyroid cancer cells.

\section{Upregulated NECTIN4 expression have a correlation with lymph node metastasis in patients with PTC}

To investigate whether NECTIN4 expression is a major risk factor for lymph node metastasis, we performed logistic regression. Univariate logistic regression analysis demonstrated that the significant variables for lymph node metastasis include expression of NECTIN4 (OR 2.925, 95\% CI 2.029-4.393, $P<0.001$ ), histological type (OR 2.383, 95\% CI 1.544-3.680, $P<0.001$ ), age (OR $0.608,95 \%$ CI $0.418-0.883$, $P=0.0009$ ), gender (OR 1.551, 95\% CI 1.022-2.353, $P=0.0039$ ), and tumor size (OR $2.525,95 \%$ CI $1.625-3.858$, $P<0.001$ ), as shown in Table 2. Multivariate logistic analysis also showed that NECTIN4 expression (OR 2.794 95\% CI $1.860-4.196, P<0.001$ ), histological type (OR $2.0695 \% \mathrm{CI}$ $1.295-3.227, P=0.002)$, age (OR $0.511,95 \%$ CI $0.366-0.828$, 
Table I Association between NECTIN4 expression and clinicopathological features in the TCGA cohort

\begin{tabular}{|c|c|c|c|}
\hline $\begin{array}{l}\text { Clinicopathol- } \\
\text { ogical } \\
\text { features }\end{array}$ & $\begin{array}{l}\text { Low } \\
\text { expression } \\
(\mathrm{N}=25 \mathrm{I})\end{array}$ & $\begin{array}{l}\text { High } \\
\text { expression } \\
(\mathrm{N}=25 \mathrm{I})\end{array}$ & $P$-value \\
\hline $\begin{array}{l}\text { Gender } \\
\text { Female } \\
\text { Male }\end{array}$ & $\begin{array}{l}181 \\
70\end{array}$ & $\begin{array}{l}187 \\
64\end{array}$ & 0.545 \\
\hline $\begin{array}{l}\text { Age (years) } \\
\text { Median }\left(\mathrm{P}_{25}-\mathrm{P}_{75}\right) \\
\quad<45 \\
\quad \geq 45\end{array}$ & $\begin{array}{l}46(34-59) \\
120 \\
131\end{array}$ & $\begin{array}{l}52(4 \mid-63) \\
105 \\
146\end{array}$ & 0.178 \\
\hline $\begin{array}{l}\text { Histological type } \\
\text { Classical } \\
\text { Other types }\end{array}$ & $\begin{array}{l}154 \\
97\end{array}$ & $\begin{array}{l}203 \\
48\end{array}$ & $<0.00 I^{*}$ \\
\hline $\begin{array}{l}\text { Multi-nodularity } \\
\text { Yes } \\
\text { No }\end{array}$ & $\begin{array}{l}110 \\
137\end{array}$ & $\begin{array}{l}116 \\
131\end{array}$ & 0.588 \\
\hline $\begin{array}{l}\text { Tumor size }(\mathrm{mm}) \\
\geq 20 \\
<20\end{array}$ & $\begin{array}{l}167 \\
83\end{array}$ & $\begin{array}{l}191 \\
59\end{array}$ & 0.017 \\
\hline $\begin{array}{l}\text { Lymph-node } \\
\text { metastasis } \\
\text { Yes } \\
\text { No }\end{array}$ & $\begin{array}{l}79 \\
|4|\end{array}$ & $\begin{array}{l}145 \\
87\end{array}$ & $<0.00 I^{*}$ \\
\hline $\begin{array}{l}\text { Distant metastasis } \\
\text { Yes } \\
\text { No }\end{array}$ & $\begin{array}{l}6 \\
245\end{array}$ & $\begin{array}{l}8 \\
243\end{array}$ & 0.588 \\
\hline $\begin{array}{l}\text { Disease stage } \\
\text { (AJCC7) } \\
\text { I+II } \\
\text { III+IV }\end{array}$ & $\begin{array}{l}194 \\
57\end{array}$ & $\begin{array}{l}139 \\
107\end{array}$ & $<0.00 I^{*}$ \\
\hline
\end{tabular}

Notes: *Chi-square test, $p$-value $<0.05$.

Abbreviations: AJCC, American Joint Committee on Cancer; TCGA, The Cancer Genome Atlas.

Table 2 Univariate logistic regression analysis for the risk of lymph node metastasis

\begin{tabular}{|l|l|l|l|}
\hline Factor & OR & $\mathbf{9 5 \%} \mathbf{~ C l}$ & P-value \\
\hline NECTIN4 expression (high vs low) & 2.925 & $2.029-4.393$ & $<0.001$ \\
Histological type & 2.383 & $1.544-3.680$ & $<0.001$ \\
Age, years ( $\leq 45$ vs $>45)$ & 0.608 & $0.418-0.883$ & 0.009 \\
Gender (male vs female) & $1.55 \mathrm{I}$ & $1.022-2.353$ & 0.039 \\
Tumor size (mm) & 2.525 & $1.625-3.858$ & $<0.00 \mathrm{I}$ \\
Multi-nodularity & 1.423 & $0.982-2.064$ & 0.063 \\
\hline
\end{tabular}

$P=0.004$ ), and tumor size (OR $2.39695 \%$ CI 1.526-3.763, $P<0.001)$ positively correlated with increased lymph node metastasis. Lymph node metastasis status was not associated
Table 3 Multivariate logistic regression analysis for risk of lymph node metastasis

\begin{tabular}{|l|l|l|l|}
\hline Factor & OR & $\mathbf{9 5 \%}$ Cl & $\begin{array}{l}\boldsymbol{P} \text { - } \\
\text { value }\end{array}$ \\
\hline NECTIN4 expression (high vs low) & 2.794 & $1.860-4.196$ & $<0.001$ \\
Histological type & 2.06 & $1.295-3.227$ & 0.002 \\
Age, years ( $\leq 45$ vs $>45)$ & $0.51 \mathrm{I}$ & $0.366-0.828$ & 0.004 \\
Gender (male vs female) & 1.533 & $0.977-2.404$ & 0.063 \\
Tumor size (mm) & 2.396 & $1.526-3.763$ & $<0.001$ \\
\hline
\end{tabular}

with gender (OR 1.533, 95\% CI 1.022-2.353, $P=0.0039$; Table 3). Therefore, upregulated NECTIN4 expression was associated with lymph node metastasis in patients with PTC.

\section{NECTIN4 gene knockdown affects the proliferation of thyroid cancer cell lines}

As the NECTIN4 gene is commonly upregulated in PTC, this gene was hypothesized to be important in tumorigenesis and progression. Therefore, we selected effective siRNA1 and siRNA2 to knock down the expression of NECTIN4 in the cell lines, and the resulting expression was evaluated using RT-qPCR analysis and western blotting (Figure 3A and B). Cell proliferation and colony formation assays were then performed. Downregulation of NECTIN4 effectively inhibited thyroid colony formation (Figure $3 \mathrm{C}$ and $\mathrm{D}, P<0.001$ ) and cell line proliferation (Figure 3E, $P<0.001$ ) compared with those in the control group.

\section{NECTIN4 gene knockdown induces the cell apoptosis of PTC cell lines in vitro}

To determine the functional significance of NECTIN4 in PTC, flow cytometry was used to determine the proportion of apoptotic cells transfected with si-NECTIN4.

Knockdown of NECTIN4 induced increased apoptosis in thyroid cancer cells (TPC1, KTC-1), especially late-stage apoptotic cells, compared with that in control cells (Figure 4).

\section{NECTIN4 regulates the migratory and invasive capacities of PTC cell lines in vitro}

Given the observed relationship between NECTIN4 expression and lymph node metastasis, we investigated the role of NECTIN4 in the migratory and invasive abilities of various thyroid cancer cell lines. As predicted, the migratory ability of si-NECTIN4 cells decreased compared with that of si-NC cells (si-NC vs Si-RNA1 vs Si-RNA2: $185.5 \pm 3.5$ vs 53.0 
A
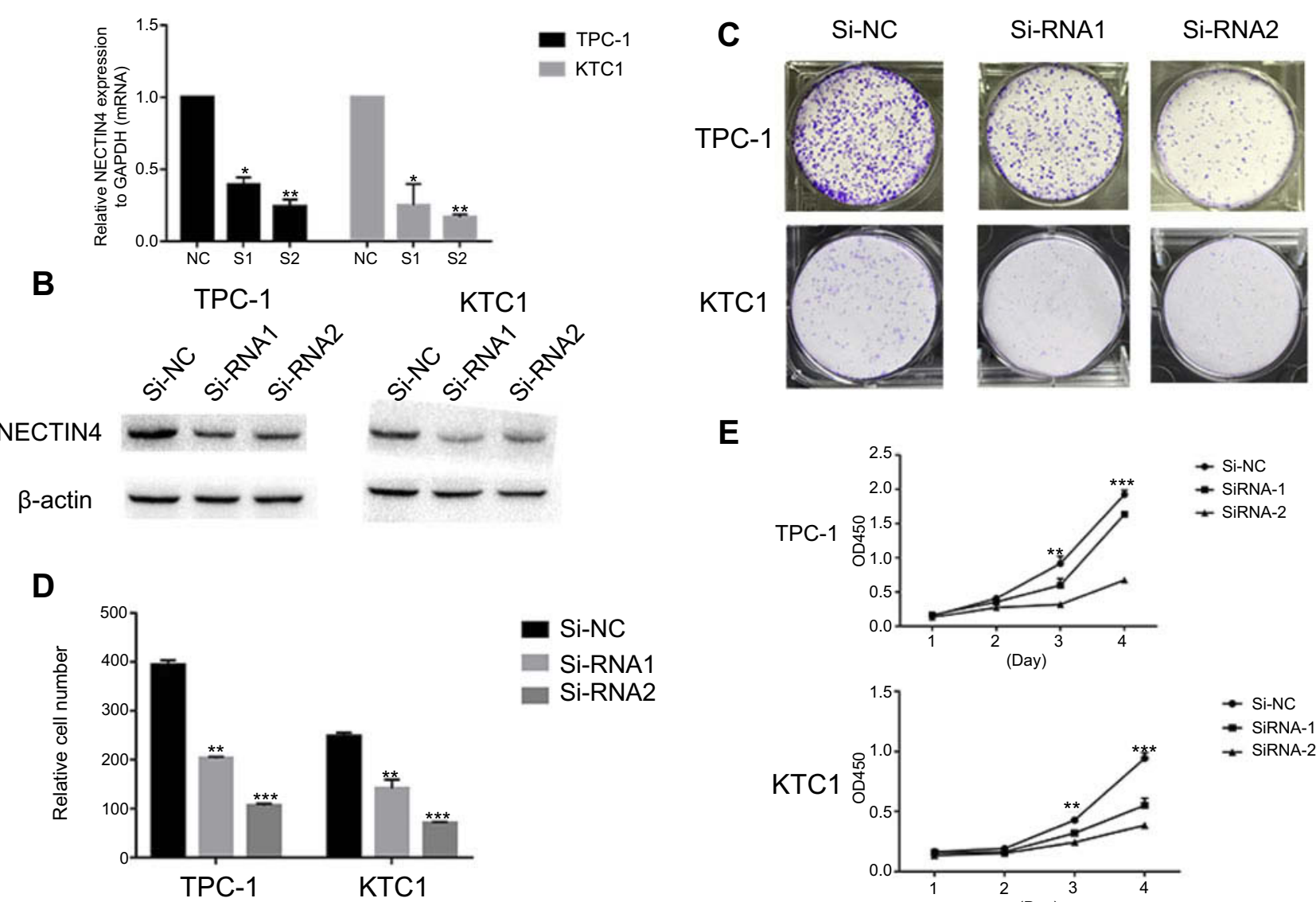

E
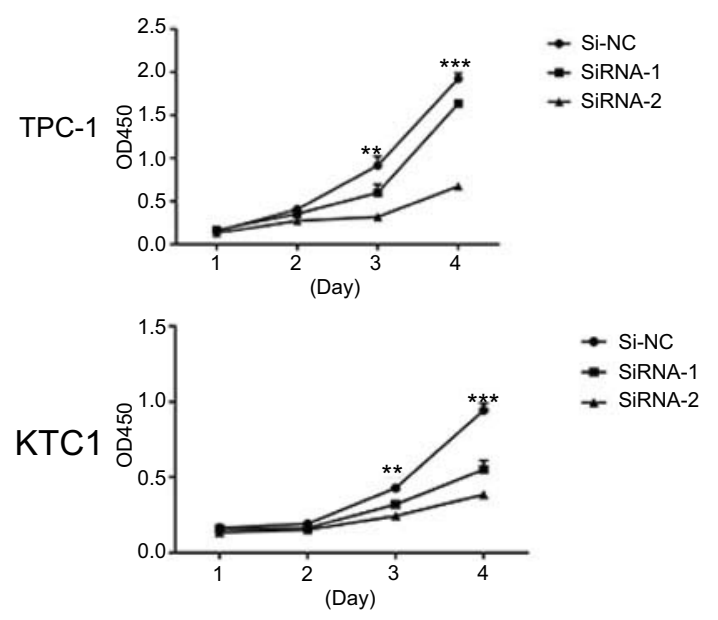

Figure 3 NECTIN4 gene knockdown affects the proliferation of thyroid cancer cell lines.

Notes: (A-B) The relative expression of NECTIN4 (compared with the GAPDH gene) in TPCI and KTC-I via qRT-PCR and WB . Compared with corresponding Si-NC group, the expression of NECTIN4 in Si-RNAI and Si-RNA2 group was lower. (C) Colony formation of NECTIN4 and si- NECTIN4 cells. (D-E) TPCI and KTC-I cell lines transfected with Si-RNA or Si-NC were cultured in 96-well plates for I-4 days and using CCK-8 measured cell proliferation. Cell proliferation was significantly suppressed in thyroid cell transfected by Si-RNAI and Si-RNA2.

\pm 1.4 vs $22.0 \pm 2.8$ (TPC-1); $154.5 \pm 3.53$ vs $55.5 \pm 2.1$ vs 22.0 \pm 2.1 (KTC-1; Figure 5A). Similarly, the invasive ability of the siNECTIN4 PTC cell lines was lower than that of the corresponding si-NC PTC cell lines (si-NC vs Si-RNA1 vs Si-RNA 2: $211.0 \pm 9.1$ vs $76.3 \pm 2.0$ vs $34.0 \pm 1.4$ (TPC-1); $106.3 \pm 5.68$ vs $27.5 \pm 6.3$ vs $20.5 \pm 2.1$ (KTC-1; Figure 5C). After transfection with si-NECTIN4, invasive ability was significantly diminished (Figure 5B and D, $P<0.001$ ). Taken together, these data suggest that NECTIN4 plays an important role in the migratory and invasive capacities of the PTC cell lines.

\section{The NECTIN4 gene regulates epithelial- mesenchymal transition (EMT)}

EMT is an indispensable process by which epithelial cells acquire the characteristics of mesenchymal cells in tumor progression and metastasis. ${ }^{20}$ As demonstrated above, the NECTIN4 gene in the TCGA cohort was significantly associated with lymph node metastasis. Therefore, we investigated the potential mechanism by which this gene contributes to PTC metastasis. We detected the protein expression of EMT-related molecules by western blot. After knocking down NECTIN4 in the PTC cell lines (TPC1, KTC-1), the si-NECTIN4 PTC cell lines showed lower Vimentin, N-cadherin, EZH2 expression (Figure 6A) and higher E-cadherin than the si-NC PTC cell lines.

Consistent with whole-cell lysates western blotting, we found that cadherins have same trend in membrane protein (Figure 6B) In addition, immunofluorescence images analysis also confirmed that si-NECTIN4 PTC cell lines have lower Vimentin, N-cadherin and higher E-cadherin than the si-NC PTC cell lines.(Figure 6C). Taking the results together, we considered that NECTIN4 could regulates epithelial-mesenchymal transition (EMT). 
A
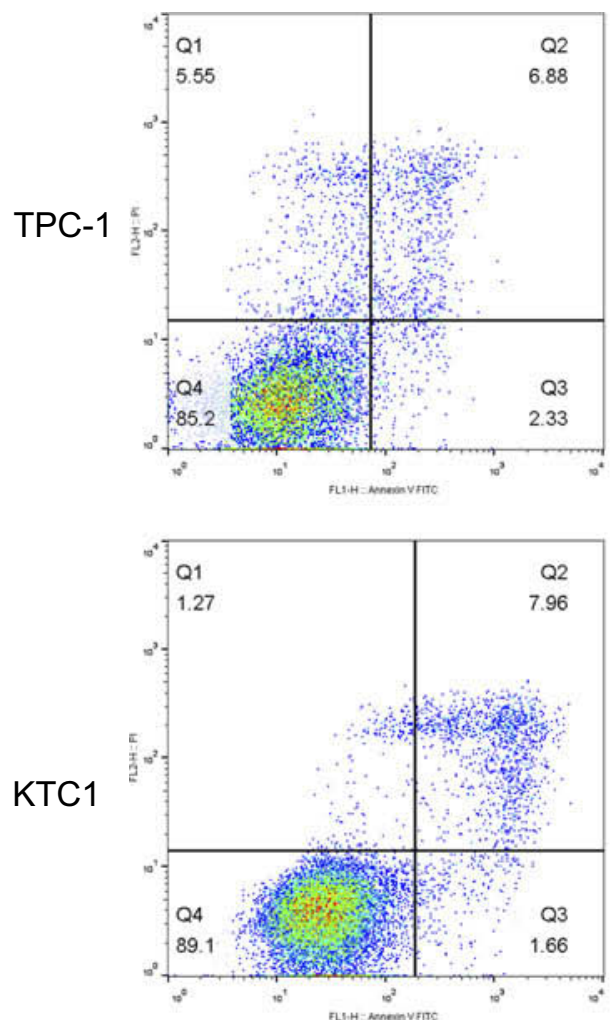

B

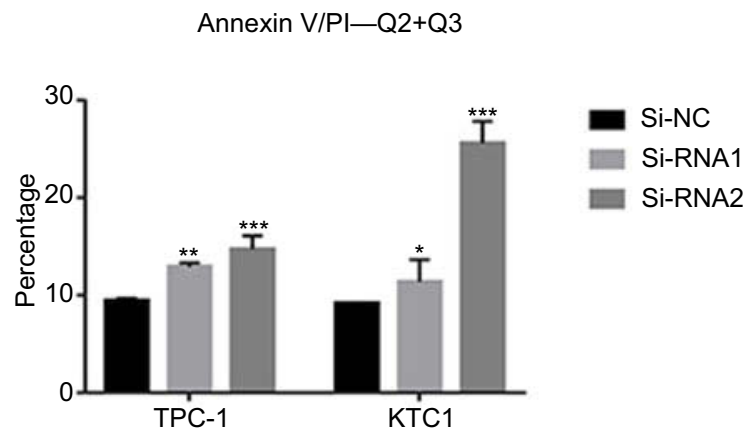

Si-RNA1
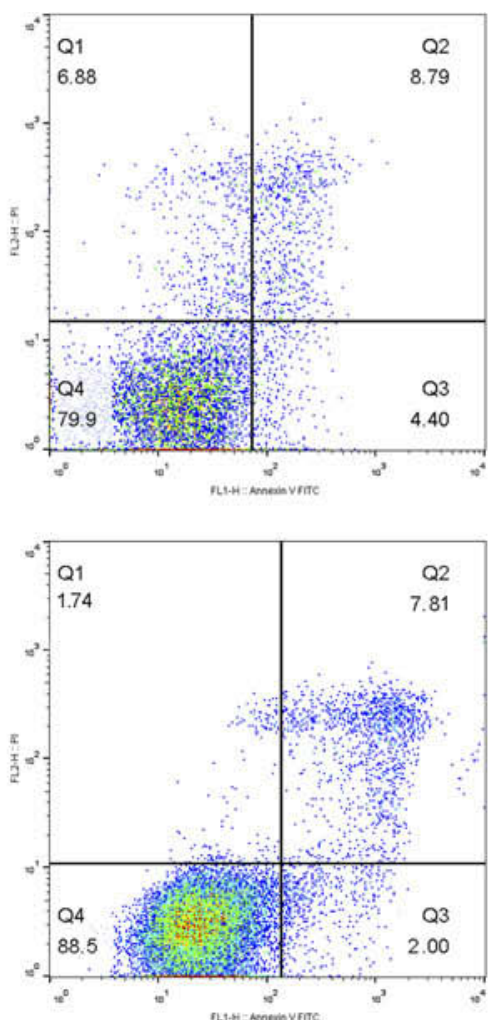

Si-RNA2
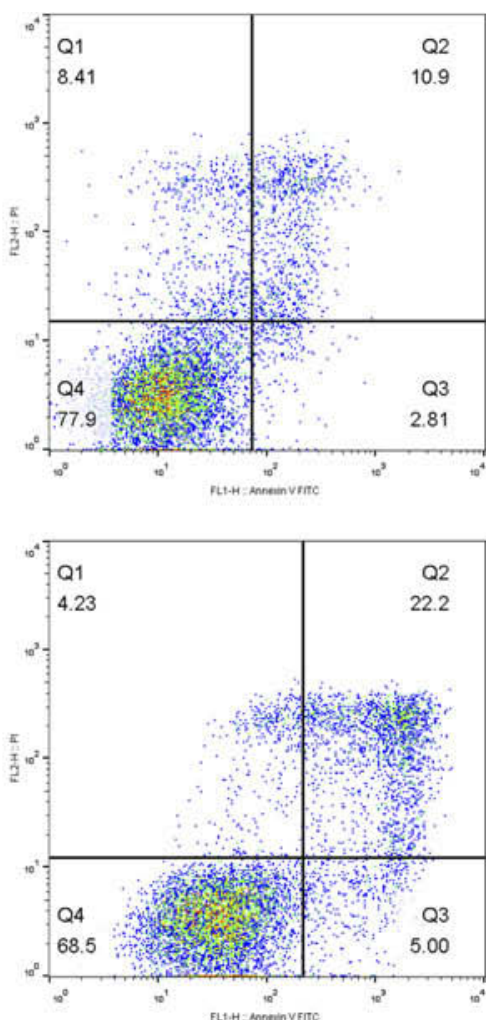

Figure 4 NECTIN4 gene knockdown induces the cell apoptosis of PTC cell lines in vitro.

Notes: (A and B) Annexin V/PI assay was applied to analyze the TPCI and KTC-I cell lines transfected with Si-NC or Si-RNAI or Si-RNA2. Knocking down NECTIN4 could increase apoptotic cell death in thyroid cancer cells. The columns represent the mean of death cell numbers from at least three independent experiments. $* P<0.05$, $* * P<0.01$ and $* * * P<0.001$ in comparison with si-NC using Student's $t$-test.

\section{Activated AKT can reverse the si-RNA knockdown effect}

The PI3K/AKT pathway is widely involved in thyroid carcinoma development and progression. ${ }^{21-23}$ It can lead various cell membrane receptor tyrosine kinases to the nucleus and regulates various cell processes, including cell proliferation, differentiation, and survival. PI3K and AKT can induce EMT, a key step toward cancer cell migration and invasion. ${ }^{24,25}$ We found that si-NECTIN4 PTC cell lines have lower p-AKT expression than si-NC PTC cell lines (Figure 7A). Therefore, we sought to investigate whether we can use a kind of AKT activator to reverse-knockout the efficiency of siRNA. SC79 can directly bind to AKT and convert it from an inactive conformation to an active one, leading to AKT hyperactivation. ${ }^{19}$ We determined that activated AKT 


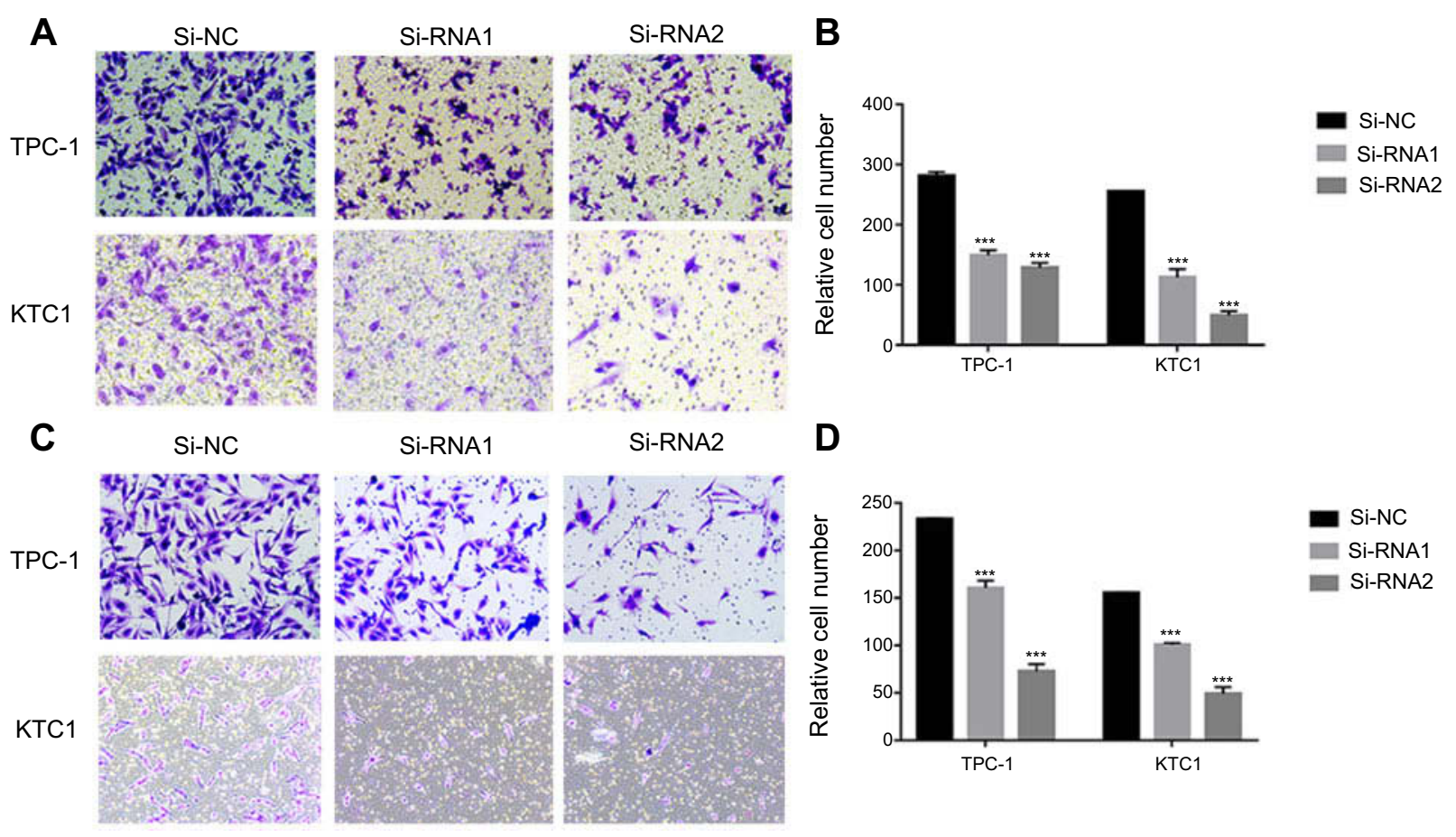

Figure 5 NECTIN4 regulates the migratory and invasive capacities of papillary thyroid cancer cell lines in vitro.

Notes: (A and C) Transwell migration and invasion assays in cells with downregulated NECTIN4 expression and their corresponding control cells. (B and D) Quantitative results of migration and invasion assays. The stained cells were manually counted from five randomly selected fields and normalized with the observed cell proliferation. $* P<0.05 ; * *<<0.01 ; * * *<0.001$ in comparison with the NC group using Student's $t$-test. Magnification is $\times 40$.

could enhance thyroid cancer (TPC1, KTC-1) cell migration and proliferation and partially reverse the si-RNA knockdown effect (Figure 7B-D). Similarly, we also used a strong inhibitor of AKT (LY 294,002) and found that siRNA could inhibit thyroid cancer (TPC1,KTC-1) proliferation and migration ability similar to AKT inhibitor (LY 294002). (Figure 7E-G)

\section{Discussion}

The global number of thyroid cancer cases is increasing by $4 \%$ annually, and a study has forecasted that thyroid cancer could surpass colorectal cancer as the fourth most common cancer diagnosis by $2030 .^{26}$ Patients with PTC, as the most common type of thyroid carcinoma, have relatively better prognosis and lower mortality rates than patients with other types of this cancer. ${ }^{27}$ Although considerable progress in genetic research had been made for thyroid cancer, the molecular mechanisms of PTC remain unclear. Over $4 \%$ of all PTC cases have an unknown oncogenic driver, and many epigenetic alterations have yet to be studied. ${ }^{28}$ In a previous study, 19 pairs of PTC tumors and adjacent normal tissues were subjected to whole-transcriptome resequencing, and NECTIN4 was found to be differentially expressed in tumor samples.
NECTIN4 plays an important role in several tumors and diseases. It is an epithelial cell receptor for canine distemper virus and has been involved in neurovirulence. ${ }^{14}$ It also leads to ectodermal dysplasia syndactyly syndrome, one of the rarer forms of ectodermal dysplasias (ED) caused by mutations in NECTIN4, which is encoded by the PVRL4 gene. ${ }^{29}$ NECTIN4 overexpression is associated with poor outcomes in lung, breast, and ovarian cancers. ${ }^{15-17}$ In addition, in primary and metastatic triplenegative breast cancer, NECTIN4 is a potential prognostic biomarker for efficient therapeutic targeting. ${ }^{30}$ However, as little is known about the function of this SNP in human thyroid cancers, the present study aimed to investigate the specific tumorigenic role of NECTIN4 in thyroid cancer.

To demonstrate the role of NECTIN4 in thyroid cancer, we examined 44 matched PTC tumor and adjacent normal tissues. The mRNA expression level of NECTIN4 was evaluated by RT-qPCR analysis, and the results obtained were consistent with the bioinformatics analysis. We also downloaded and analyzed clinical data in the "Biotab" format from the TCGA portal and found that the NECTIN4 gene is significantly upregulated in PTC tissues compared with that in the adjacent normal thyroid tissues in both the validated and TCGA cohorts. Logistic regression analysis indicated that 
A

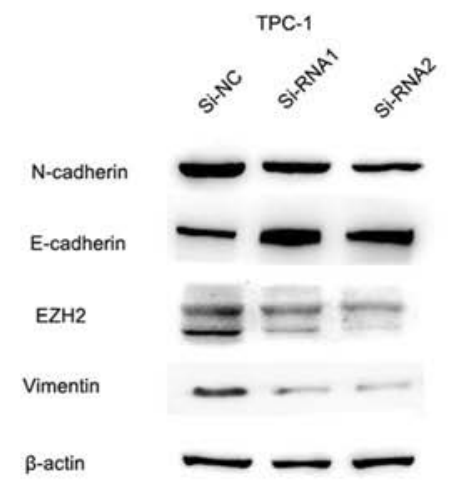

B

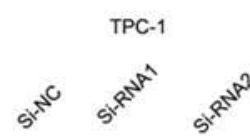

N-cadherin

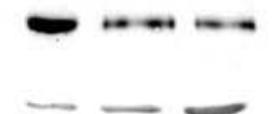

$\mathrm{Na}+/ \mathrm{K}+-\mathrm{ATPase}$

C
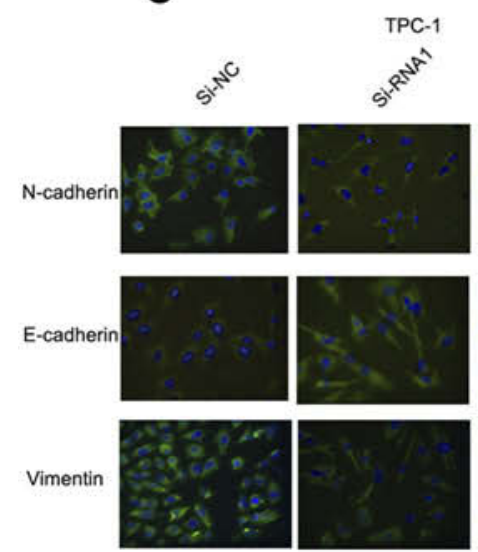
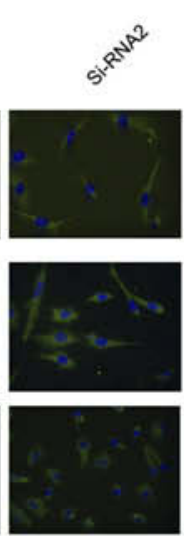
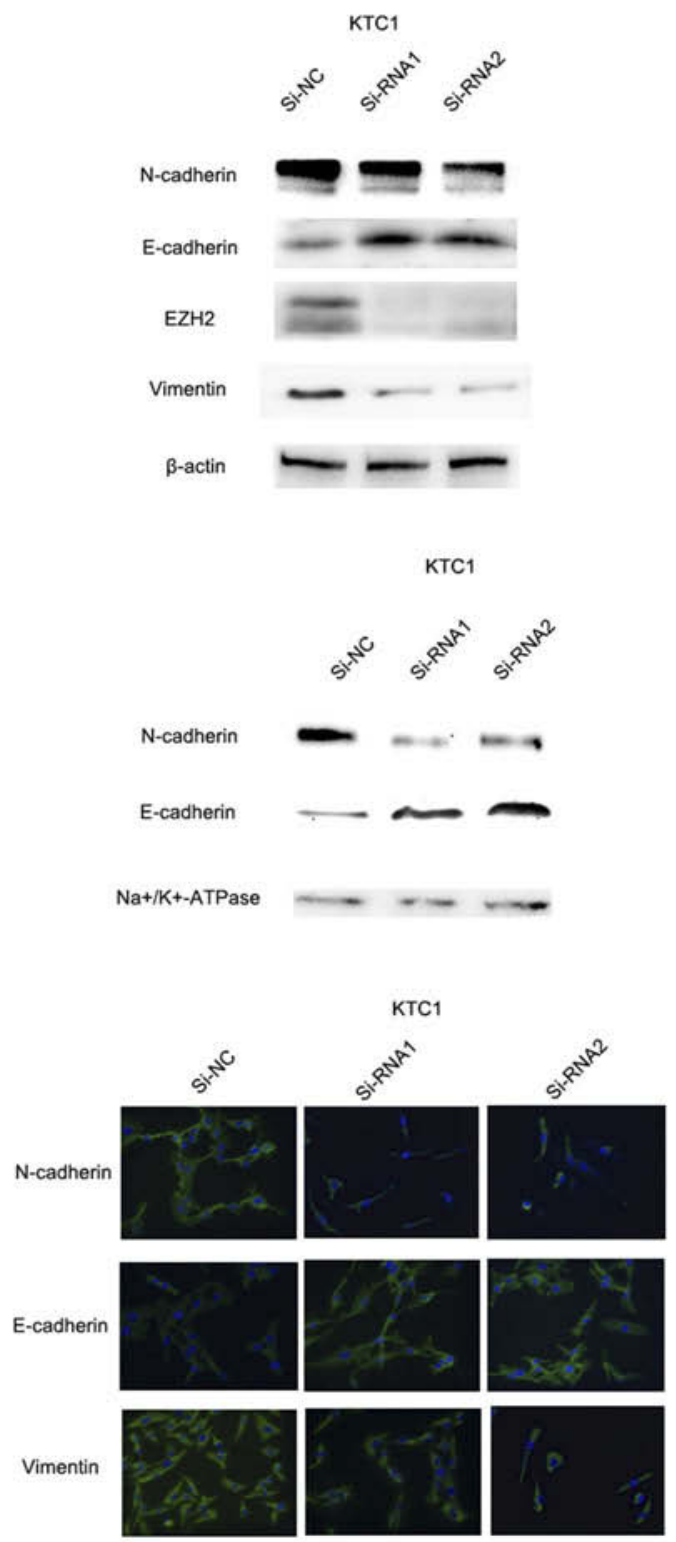

Figure 6 The NECTIN4 gene regulates epithelial-mesenchymal transition.

Notes: (A) The influence of NECTIN4 expression on the levels of E-cadherin, N-cadherin, Vimentin and EZH2 in TPCI and KTC-I (transfected with si-RNAI, si-RNA 2 or si-NC) by western blot. (B) The influence of NECTIN4 expression on the levels of E-cadherin and N-cadherin in TPCI and KTC-I membrane fraction of the cell lysate by western blot. (C) Immunofluorescence images analysis of Vimentin, $\mathrm{N}$-cadherin and E-cadherin in the plasma membrane fraction. Magnification is $\times 40$.

high NECTIN4 expression is a risk factor for lymph node metastasis in patients with PTC. The results of the cell-based assays also confirm the hypothesis that NECTIN4 is a novel oncogene in PTC.

Invasion and migration are the most important biological features of thyroid carcinoma. In our study, we demonstrated that downregulated NECTIN4 expression inhibits cell proliferation and colony formation, decreases migration and invasion, and induces cell apoptosis. These results are consistent with the clinicopathological features showing the association of NECTIN4 with lymph node metastasis and increased risk of metastasis.

EMT is a process by which cells lose epithelial characteristics, such as cell polarity, and acquire mesenchymal properties, such as increased motility. In various cancers, such as prostate cancer, EMT is associated with metastasis, and the underlying pathways and mechanisms leading to EMT appear to vary among different cancers. ${ }^{26}$ The levels of the EMTrelated factors E-cadherin, N-cadherin, and EZH2 could change in various cancers. ${ }^{27-30}$ We detected the protein 


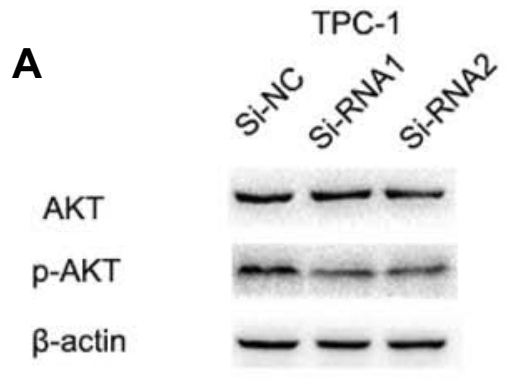

B
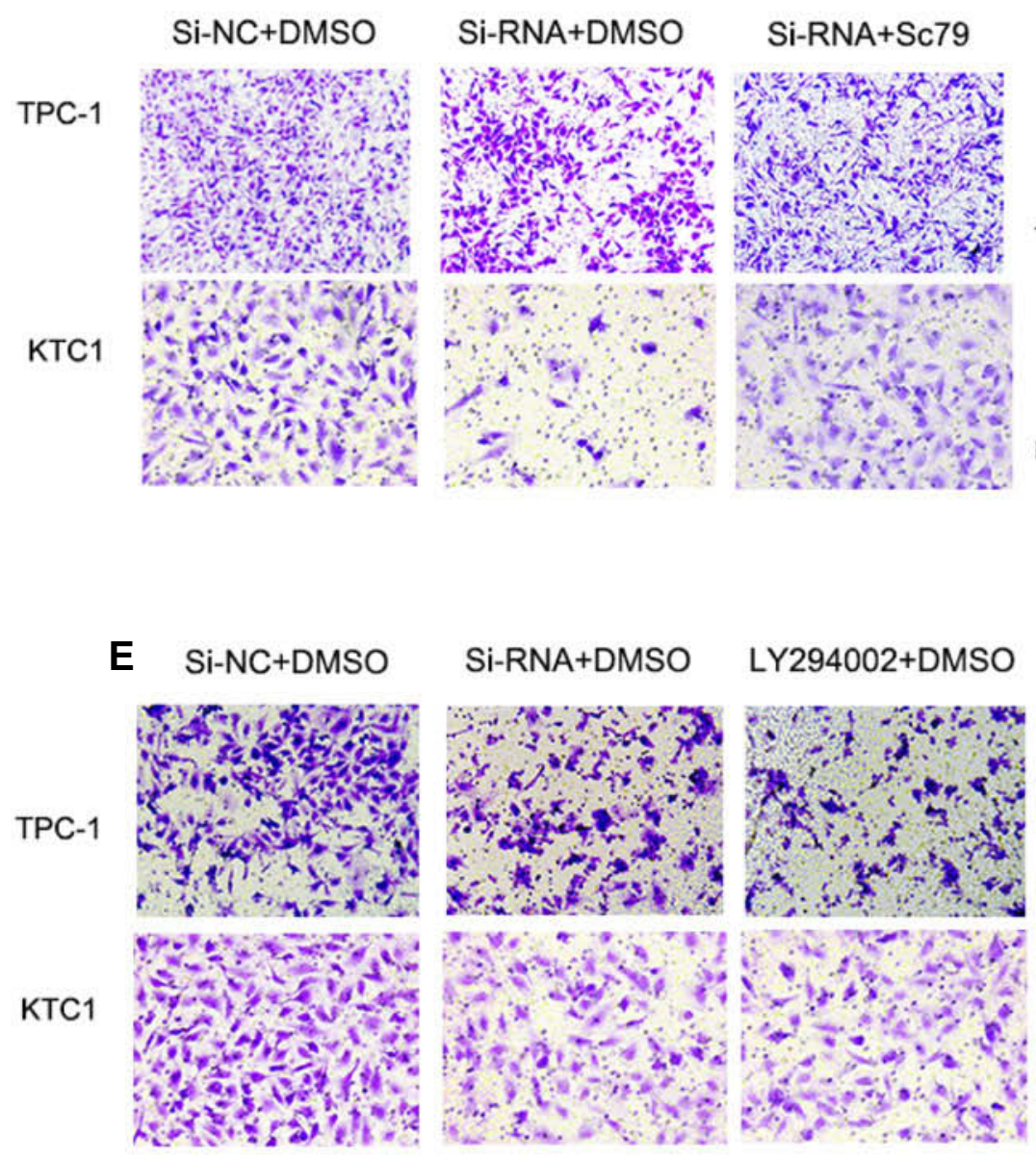
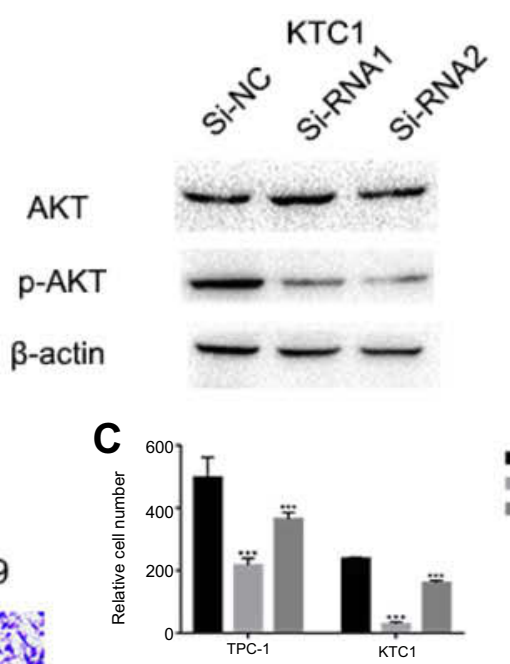

- Si-NC+DMSO = Si-RNA+DMSO - Si-RNA+SC79

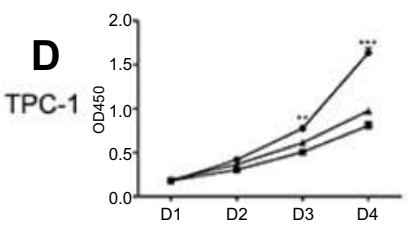

- Si-NC+DMSO

- Si-RNA+DMSO

- Si-RNA+SC79

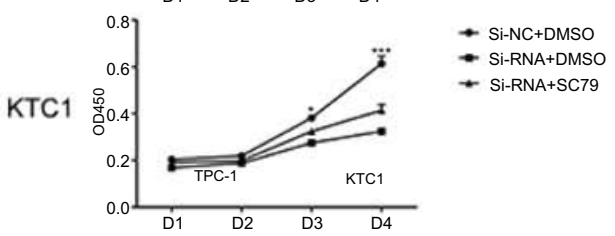

F

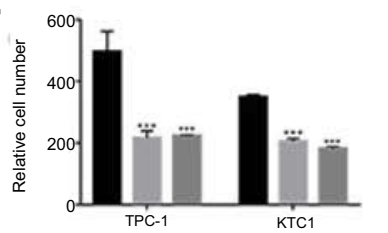

- Si-NC+DMSO

= Ly294002+DMSO

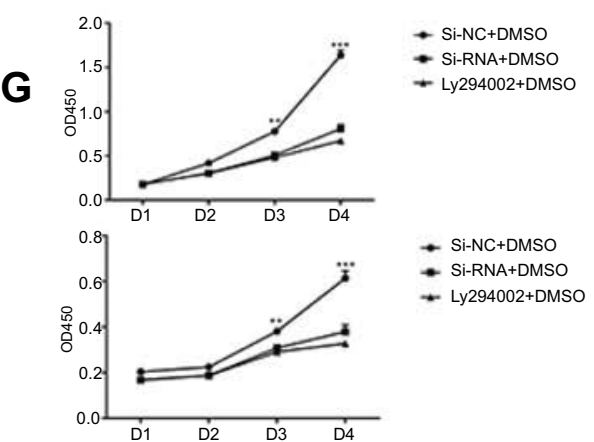

Figure 7 Activated AKT can reverse the si-RNA knockdown effect.

Notes: (A) The influence of NECTIN4 expression on the levels of NECTIN4, AKT, p-AKT in TPCI and KTC-I (transfected with si-RNAI, si-RNA2 or si-NC) by western blot. (B and C) Transwell migration in cells with group of downregulated NECTIN4 expression, group of control cells and group of SC79 activated cells. The concentration of SC79 was $10 \mathrm{mM}$, and all reagents were dissolved in DMSO. Quantitative results of migration assays. (D) The group of downregulated NECTIN4 expression, group of control cells and group of SC79 activated cells were cultured in 96-well plates for I-4 days and using CCK-8 measured cell proliferation. (E and F) Transwell migration in cells with group of downregulated NECTIN4 expression, group of control cells and group of LY294002 inhibit cells. The concentration of SC79 was $25 \mathrm{mM}$, and all reagents were dissolved in DMSO. Quantitative results of migration assays. (G) The group of downregulated NECTIN4 expression, group of control cells and group of LY294002 inhibit cells were cultured in 96-well plates for I-4 days and using CCK-8 measured cell proliferation. Magnification is $\times 40$.

expression of EMT-related molecules by western blot and immunofluorescence and found high Vim and low $\mathrm{N}$-cadherin and EZH2 expression in the si-NECTIN4 cell lines. Moreover, PI3K and AKT can induce EMT, which plays an essential role in cancer cell migration and invasion. ${ }^{24,25}$ We demonstrated that si-NECTIN4 cell lines 
show lower $p$-AKT expression than si-NC PTC cell lines. Furthermore, we used SC79, an AKT phosphorylation activator, to promote cell migration and invasion and reverse the knockdown effect caused by Si-RNA. Similarly, we used a strong AKT inhibitor (LY 294002) and found that siRNA could inhibit thyroid cancer (TPC1,KTC-1) proliferation and migration ability similar to AKT inhibitor.

\section{Limitations}

The current study presents several limitations. First, more tumor samples are necessary to analyze the correlation of NECTIN4 with clinical parameters and confirm its role in PTC metastasis. Second, the number of patients recruited was limited, and additional cases are required to provide more rigorous results. Finally, but most importantly, the mechanism of NECTIN4 in tumorigenesis and metastasis has yet to be elucidated and requires further investigation.

\section{Conclusion}

The present study investigated the association between NECTIN4 and lymph node metastasis, as well as the function of NECTIN4 in vitro. NECTIN4 was significantly associated with lymph node metastasis, resulting in increased tumorigenesis and metastasis. These findings provide a potential diagnostic and therapeutic molecular marker for PTC.

\section{Ethical approval and consent to participate}

Ethical approval for this study was obtained from the Ethics Committee of the First Affiliated Hospital of Wenzhou Medical University. Written informed consent was obtained from each individual participant. This research was thoroughly approved by and conducted in accordance with the ethical standards of the Institutional Review Board of First Affiliated Hospital of Wenzhou Medical University (approval no. 2012-57).

\section{Availability of data and materials}

The data sets supporting the conclusions of this article are included within this article and its additional images. Raw data are available on the main electronic data storage system of First Affiliated Hospital of Wenzhou Medical University and access can be provided upon request to the authors.

\section{Acknowledgment}

This study was funded by the Natural Science Foundation of Zhejiang Province (LY18H160053, LY17H160053 and
LY18H160053) and the Science and Technology Project of Wenzhou (Y20170030).

\section{Disclosure}

The authors report no conflicts of interest in this work.

\section{References}

1. Siegel RL, Miller KD, Jemal A. Cancer statistics, 2017. CA Cancer J Clin. 2017;67(1):7-30. doi:10.3322/caac.21387

2. Ito Y, Nikiforov YE, Schlumberger M, Vigneri R. Increasing incidence of thyroid cancer: controversies explored. Nat Rev Endocrinol. 2013;9(3):178-184. doi:10.1038/nrendo.2012.257

3. Chen W, Zheng R, Baade PD, et al. Cancer statistics in China, 2015. CA Cancer J Clin. 2016;66(2):115-132. doi:10.3322/caac.21338

4. La Vecchia C, Malvezzi M, Bosetti C, et al. Thyroid cancer mortality and incidence: a global overview. Int $J$ Cancer. 2015;136 (9):2187-2195. doi:10.1002/ijc.29251

5. Hinson AM, Massoll NA, Jolly LA, Stack BC Jr., Bodenner DL, Franco AT. Structural alterations in tumor-draining lymph nodes before papillary thyroid carcinoma metastasis. Head Neck. 2017;39 (8):1639-1646. doi:10.1002/hed.24807

6. Leboulleux S, Rubino C, Baudin E, et al. Prognostic factors for persistent or recurrent disease of papillary thyroid carcinoma with neck lymph node metastases and/or tumor extension beyond the thyroid capsule at initial diagnosis. J Clin Endocrinol Metab. 2005;90(10):5723-5729. doi:10.1210/jc.2005-0285

7. Schneider DF, Chen H. New developments in the diagnosis and treatment of thyroid cancer. CA Cancer J Clin. 2013;63 (6):374-394. doi:10.3322/caac.21195

8. Kimura ET, Nikiforova MN, Zhu Z, Knauf JA, Nikiforov YE, Fagin JA. High prevalence of BRAF mutations in thyroid cancer: genetic evidence for constitutive activation of the RET/PTC-RASBRAF signaling pathway in papillary thyroid carcinoma. Cancer Res. 2003;63(7):1454-1457.

9. Vuong HG, Altibi AM, Duong UN, et al. Role of molecular markers to predict distant metastasis in papillary thyroid carcinoma: promising value of TERT promoter mutations and insignificant role of BRAF mutations-a meta-analysis. Tumour Biol. 2017;39 (10): 1010428317713913 . doi:10.1177/1010428317713913

10. Melo M, Da Rocha AG, Vinagre J, et al. TERT promoter mutations are a major indicator of poor outcome in differentiated thyroid carcinomas. J Clin Endocrinol Metab. 2014;99(5):E754-E765. doi:10.1210/jc.2013-3734

11. Decaussin-Petrucci M, Descotes F, Depaepe L, et al. Molecular testing of BRAF, RAS and TERT on thyroid FNAs with indeterminate cytology improves diagnostic accuracy. Cytopathology. 2017;28 (6):482-487. doi:10.1111/cyt.12493

12. Wang QX, Chen ED, Cai YF, et al. A panel of four genes accurately differentiates benign from malignant thyroid nodules. $J$ Exp Clin Cancer Res. 2016;35(1):169. doi:10.1186/s13046-016-0444-6

13. Takai Y, Miyoshi J, Ikeda W, Ogita H. Nectins and nectin-like molecules: roles in contact inhibition of cell movement and proliferation. Nat Rev Mol Cell Biol. 2008;9(8):603-615. doi: $10.1038 / \mathrm{nrm} 2457$

14. Pratakpiriya W, Seki F, Otsuki N, et al. Nectin4 is an epithelial cell receptor for canine distemper virus and involved in neurovirulence. $J$ Virol. 2012;86(18):10207-10210. doi:10.1128/ JVI.00824-12

15. Rajc J, Gugic D, Frohlich I, Marjanovic K, Dumencic B. Prognostic role of Nectin-4 expression in luminal B (HER2 negative) breast cancer. Pathol Res Pract. 2017;213(9):1102-1108. doi:10.1016/j. prp.2017.07.019 
16. Derycke MS, Pambuccian SE, Gilks CB, et al. Nectin 4 overexpression in ovarian cancer tissues and serum: potential role as a serum biomarker. Am J Clin Pathol. 2010;134(5):835-845. doi:10.1309/ AJCPGXK0FR4MHIHB

17. Takano A, Ishikawa N, Nishino R, et al. Identification of nectin-4 oncoprotein as a diagnostic and therapeutic target for lung cancer. Cancer Res. 2009;69(16):6694-6703. doi:10.1158/0008-5472.CAN-09-0016

18. Kanzaki N, Ogita H, Komura $\mathrm{H}$, et al. Involvement of the nectin-afadin complex in PDGF-induced cell survival. J Cell Sci. 2008;121(Pt 12):2008-2017. doi:10.1242/jcs.024620

19. Jo H, Mondal S, Tan D, et al. Small molecule-induced cytosolic activation of protein kinase Akt rescues ischemia-elicited neuronal death. Proc Natl Acad Sci U S A. 2012;109(26):10581-10586. doi:10.1073/pnas. 1202810109

20. Thiery JP, Sleeman JP. Complex networks orchestrate epithelial-mesenchymal transitions. Nat Rev Mol Cell Biol. 2006;7 (2):131-142. doi:10.1038/nrm1835

21. Campos M, Kool MM, Daminet S, et al. Upregulation of the PI3K/ Akt pathway in the tumorigenesis of canine thyroid carcinoma. $J$ Vet Intern Med. 2014;28(6):1814-1823. doi:10.1111/jvim.12435

22. Hou P, Liu D, Shan Y, et al. Genetic alterations and their relationship in the phosphatidylinositol 3-kinase/Akt pathway in thyroid cancer. Clin Cancer Res. 2007;13(4):1161-1170. doi:10.1158/1078-0432.CCR-06-1125

23. Santarpia L, El-Naggar AK, Cote GJ, Myers JN, Sherman SI. Phosphatidylinositol 3-kinase/akt and ras/raf-mitogen-activated protein kinase pathway mutations in anaplastic thyroid cancer. J Clin Endocrinol Metab. 2008;93(1):278-284. doi:10.1210/jc.2007-1076
24. Larue L, Bellacosa A. Epithelial-mesenchymal transition in development and cancer: role of phosphatidylinositol 3' kinase/AKT pathways. Oncogene. 2005;24(50):7443-7454. doi:10.1038/sj. onc. 1209091

25. Yan W, Fu Y, Tian D, et al. PI3 kinase/Akt signaling mediates epithelial-mesenchymal transition in hypoxic hepatocellular carcinoma cells. Biochem Biophys Res Commun. 2009;382(3):631-636. doi:10.1016/j.bbrc.2009.03.088

26. Rahib L, Smith BD, Aizenberg R, Rosenzweig AB, Fleshman JM, Matrisian LM. Projecting cancer incidence and deaths to 2030: the unexpected burden of thyroid, liver, and pancreas cancers in the United States. Cancer Res. 2014;74(11):2913-2921. doi:10.1158/ 0008-5472.CAN-14-0155

27. Xing M. Molecular pathogenesis and mechanisms of thyroid cancer. Nat Rev Cancer. 2013;13(3):184-199. doi:10.1038/ nrc3431

28. Cancer Genome Atlas Research N. Integrated genomic characterization of papillary thyroid carcinoma. Cell. 2014;159(3):676-690. doi:10.1016/j.cell.2014.09.050

29. Raza SI, Nasser Dar R, Shah AA, Ahmad W. A novel homozygous nonsense mutation in the PVRL4 gene and expansion of clinical spectrum of EDSS1. Ann Hum Genet. 2015;79(2):92-98. doi:10.1111/ahg.12094

30. M-Rabet M, Cabaud O, Josselin E, et al. Nectin-4: a new prognostic biomarker for efficient therapeutic targeting of primary and metastatic triple-negative breast cancer. Ann Oncol. 2017;28(4):769-776. doi:10.1093/annonc/mdw678

\section{Publish your work in this journal}

Cancer Management and Research is an international, peer-reviewed open access journal focusing on cancer research and the optimal use of preventative and integrated treatment interventions to achieve improved outcomes, enhanced survival and quality of life for the cancer patient.
The manuscript management system is completely online and includes a very quick and fair peer-review system, which is all easy to use. Visit http://www.dovepress.com/testimonials.php to read real quotes from published authors. 